THE SCIENTIFIC PROCESS 


\title{
THE SCIENTIFIC PROCESS
}

\author{
by
}

STEPHEN DAVID ROSS

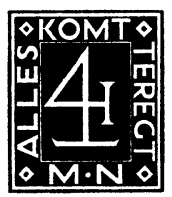

MARTINUS NIJHOFF / THE HAGUE / I97I 
ISBN-13: 978-90-247-5026-9

e-ISBN-13: 978-94-010-2987-2

DOI: $10.1007 / 978-94-010-2987-2$

(C) I97I by Martinus Nijhoff, The Hague, Netherlands

All rights reserved, including the right to translate or to reproduce this book or parts thereof in any form 


\section{CONTENTS}

I. THE RISE OF SCIENCE
A. The Enterprise of Science
B. The Beginnings
C. The Scientific Attitude
D. The Scientific Quest
E. Science as Process

II. KNOWLEDGE AND FACT

A. The Doctrine of Fact

B. A Closed Ontology

C. Truth

III. THE WAY OF KNOWING

A. Activity and Development $\quad 38$

B. Knowing

C. An Open Ontology

D. Difficulties

E. Other Aspects of Knowing

IV. THE OPEN DIMENSION OF PROCESS
A. Openness
B. Temporality
$6 \mathrm{I}$
C. The Cumulation of Process
64

$\begin{array}{ll}\text { V. THE PROCESS OF SCIENCE } & 68\end{array}$
A. The Context of Scientific Investigation
68
B. The Conditionality of Science
73
C. Logical Order 
D. The Principle of Causality $\quad 82$

E. The Cumulation of Science $\quad 88$

F. Scientific Validity 90

G. The Particular Sciences 95

H. Other Domains of Understanding ro3

VI. EVIDENCE

A. Perspective 108

B. The Perspective of Science Iro

C. Induction $\quad$ II5

D. The Compulsion of Science $\quad$ I22

E. The Compulsion of Evidence $\quad$ I25

F. Theoretical Validity $\quad$ I35

G. Objectivity $\quad$ I37

H. The Rational Life $\quad$ I47 


\section{INTRODUCTION}

Some preliminary observations must be made concerning the nature and purpose of this study. What I have attempted here is an essay in the metaphysics of science, and not the "philosophy of science." Rather than concentrating on the details of theory-construction and the formal structure of scientific systems, I have treated science as an enterprise, a developing process within human experience. I have used such an approach in order to analyze science in its relationship to other human enterprises, such as art and philosophy, and to clarify its unique goals and characteristics. Often the concepts employed in descriptions of scientific methods are conceived too narrowly; by broadening the focus of attention I have attempted to characterize in a fairly general fashion the goals and methods of science. This has led to formulations which may seem at first glance to depart radically from some "wellestablished" distinctions of the philosophy of science. I hope that it will be clear, however, that such formulations arise at a different level of analysis and concern very different problems from those of the logic of science. In particular, I am concerned with the general goals of science. These must not be confused with the narrower principles of method employed in science at any given time.

The main purpose of this essay, then, is not so much to add to the details of our understanding of science when isolated in its subject matters, goals, and methods from the rest of human experience, as to place the concepts, methods, and aims of science in their relationship to other human activities. Above all, I hope that this essay contributes to an understanding of the sense in which we speak of science as knowledge, and hesitate to do the same for art and philosophy. In this light, it is more an essay in epistemology with special emphasis on science than an examination of the philosophy of science. Our culture has become so imbued with science and its fruits that it is essential to take a larger look at the meaning of science, instead of concentrating on its internal and unique characteristics. 